\title{
Previdência Social: fatores que explicam os resultados financeiros*
}

\author{
Anderson Ribeiro Leite** \\ Walter Lee Ness Jr.*** \\ Marcelo Cabus Klotzle****
}

SumÁrio: 1. Introdução; 2. Reforma da Previdência: breve novo episódio da série; 3. Revisão da literatura; 4. Variáveis previdenciárias; 5 . Tratamento e análise dos dados; 6. Modelos selecionados; 7. Conclusões.

Summary: 1. Introduction; 2. Welfare reform: short new episode of the series; 3. Literature review; 4 . Social security variables; 5 . Data treatment and analysis; 6. Selected models; 7. Conclusions.

Palavras-chave: Previdência Social; benefícios previdenciários; receitas previdenciárias; fatores.

KEYWORDs: Social security; benefits; revenues; factors.

Este artigo apresenta uma análise desenvolvida para identificar fatores que exercem influência no resultado financeiro do Regime Geral de Previdência Social (RGPS), com destaque para os efeitos nos componentes de receitas, benefícios e saldos previdenciários. Para confirmar as afirmações encontradas na literatura, foram usadas séries de valores mensais dos fatores selecionados, além das receitas, benefícios e saldos previdenciários contendo observações no período de 1995 a 2006. Os resultados

\footnotetext{
* Artigo recebido em nov. 2008 e aceito em nov. 2009.

** Mestre em administração de empresas pela Pontifícia Universidade Católica (PUC-RJ). Endereço: Rua Prof. Álvaro Rodrigues, 460 - Botafogo - CEP 22280-040, Rio de Janeiro, RJ, Brasil. E-mail: andribleite@yahoo.com.

*** Ph.D em economia pelo MIT (EUA). Professor de finanças do IAG - Departamento de Administração da Pontifícia Universidade Católica do Rio de Janeiro (PUC-Rio). Endereço: Rua Marquês de São Vicente, 225 - Gávea - CEP 22453-900, Rio de Janeiro, RJ, Brasil. E-mail: ness@iag.puc-rio.br.

**** Ph.D em economia pela Katholische Universität Eichstätt (Alemanha). Professor de finanças do IAG - Departamento de Administração da Pontifícia Universidade Católica do Rio de Janeiro (PUC-Rio). Endereço: Rua Marquês de São Vicente, 225 - Gávea - CEP 22453-900, Rio de Janeiro, RJ, Brasil. E-mail: klotzle@iag.puc-rio.br.
} 
confirmaram a influência dos fatores demográficos, salário mínimo, rendimentos, trabalho informal e desemprego nas receitas, benefícios e no resultado financeiro do RGPS.

Social security: factors that explain the results

This article presents a set of factors that explain the financial results of the General Social Security Regime in Brazil, focusing on revenue, benefit and global results. To test the findings encountered in the literature, monthly time series of the selected factors were used in addition to revenues, benefits and the global financial result covering the period from 1995 to 2006. The results confirmed the influence of demographic factors, minimum wages, salaries, informal labor and unemployment on revenues, benefits and the global financial result of the GSSR.

\section{Introdução}

Este trabalho identifica fatores que influenciam no resultado financeiro da Previdência Social. Para isso, apresentamos a estrutura atual do sistema previdenciário brasileiro e a evolução que deu origem a ele. Esta introdução é útil para contextualizar o trabalho e compreender suas delimitações, uma vez que a Previdência Social brasileira é composta por diversas instituições submetidas a um conjunto enorme de regras que são atualizadas frequentemente e determinam um processo dinâmico quando observado no longo prazo. Além disso, o fato de que a estrutura atual retrata um instante de um processo evolutivo evidencia a relevância do artigo na medida em que ele agrega conhecimento útil para a administração pública enfrentar os desafios das reformas previdenciárias. Vejamos, então, uma brevíssima história da previdência no mundo e no Brasil.

O primeiro sistema previdenciário formal baseado em contribuições prévias como requisito obrigatório para se obter a condição de participante surgiu na Alemanha ao fim do século XIX (Schwarzer, 2000). Na primeira metade do século XX, com a experiência da depressão econômica ocorrida entre as guerras mundiais, surgiram os modelos universalizantes - que contemplam benefícios para cidadãos sem exigência de contribuições prévias (Santos, 2004). A partir da constatação de que necessidades e contingências individuais afetam a sociedade de maneira geral, se estabeleceu o conceito de seguridade social que, segundo Ness e colaboradores (1992), é um conjunto de ações do poder público e da sociedade destinado a assegurar ao cidadão e aos seus dependentes o direito à saúde, à previdência e à assistência social. 
No Brasil, as instituições previdenciárias organizaram-se a partir da década de 1920 por categorias profissionais segundo o modelo contributivo clássico. Até a década de 1950 houve forte expansão tanto da quantidade de instituições e filiados quanto da influência do Estado sobre elas, a ponto de serem convocadas a participar do financiamento da construção de Brasília. As décadas de 1960 e 1970 caracterizaram-se pela unificação das normas e da gestão, época em que foi criado o Sistema Nacional de Previdência e Assistência Social (Sinpas) integrando várias funções e entidades especializadas. Merece destaque também a implantação do conceito de seguridade social na Constituição de 1988 e a consolidação, na década seguinte, da Previdência como forma de seguro social (MPS, 2004).

O sistema previdenciário brasileiro atual é dividido em quatro blocos. O primeiro deles é constituído por um regime que atende ao setor privado, conhecido como Regime Geral de Previdência Social (RGPS). O segundo bloco corresponde ao sistema dos servidores públicos da União, conhecido como Regime Jurídico Único (RJU). Um terceiro bloco reúne os diversos sistemas de servidores estatutários estaduais e municipais. O quarto bloco, de caráter privado e facultativo, é constituído pelos fundos de pensão patrocinados por empresas privadas ou estatais (previdência complementar fechada) e pelas entidades abertas de previdência complementar (Giambiagi e colaboradores, 2004).

Esse pequeno histórico, além de nivelar conhecimentos sobre o objeto deste artigo, demonstra que "as regras que dão forma concreta a esquemas previdenciários são resultado de consensos sociopolíticos e mudam conforme a evolução da própria sociedade" (Schwarzer, 2000:9). É de se esperar, portanto, que a Previdência Social brasileira seja objeto de avaliações periódicas e de reformulações para mantê-la adaptada ao pacto social vigente. Se as reformas são inevitáveis, que sejam bem fundamentadas e, assim, mais eficazes e menos sujeitas a interesses ou opiniões parciais.

Mas o tema não se restringe às fronteiras brasileiras, pois a maioria dos sistemas formais de seguridade social é gerenciada pelo governo, paga benefícios definidos baseados nas rendas e nos anos de serviço dos trabalhadores e é financiada por impostos incidentes sobre a folha de pagamento (James, 2001). Também na maioria dos países, segundo Thompson (2000), discute-se a adequação dos sistemas previdenciários às transformações demográficas e socioeconômicas com o objetivo de garantir a proteção social dentro de padrões de sustentabilidade financeira e atuarial.

Por tudo isso, espera-se que este artigo agregue conhecimento sobre a dinâmica previdenciária, identificando ou confirmando parâmetros relevantes que possam ser úteis aos administradores públicos na elaboração e defesa das propostas de reforma. 
O artigo está dividido em sete partes, incluindo esta introdução: após uma breve discussão sobre a necessidade de uma reforma da Previdência no Brasil, é feita uma revisão da literatura especializada com a intenção de verificar fatores supostamente relevantes para a Previdência Social, além de selecionar, para cada fator citado, um indicador adequado para representá-lo numa análise quantitativa. A seção 4 consiste em discutir as variáveis previdenciárias relevantes neste artigo, ou seja, as receitas, os benefícios e os resultados previdenciários. Na seção 5 se discute a metodologia empregada no estudo, para em seguida submeter esses dados à análise de regressão múltipla aplicada à luz do referencial teórico da econometria de séries temporais, além de discutir os principais resultados. Por fim, um resumo e discussão dos principais resultados.

\section{Reforma da Previdência — breve novo episódio da série}

Uma reforma da Previdência brasileira depende da agenda política, mas a necessidade de realizá-la já é reconhecida tanto pelos resultados financeiros negativos quanto pelas comparações internacionais que demonstram uma situação atípica da Previdência brasileira em relação a regimes semelhantes. Os gastos previdenciários brasileiros são proporcionalmente maiores quando tomados em relação ao Produto Interno Bruto (PIB) e comparados aos de outros países.

Conforme demonstra a figura 1, extraída de Giambiagi (2007:93), o Brasil encontra-se na posição mais desfavorável entre os países analisados.

Gasto previdenciário de países selecionados

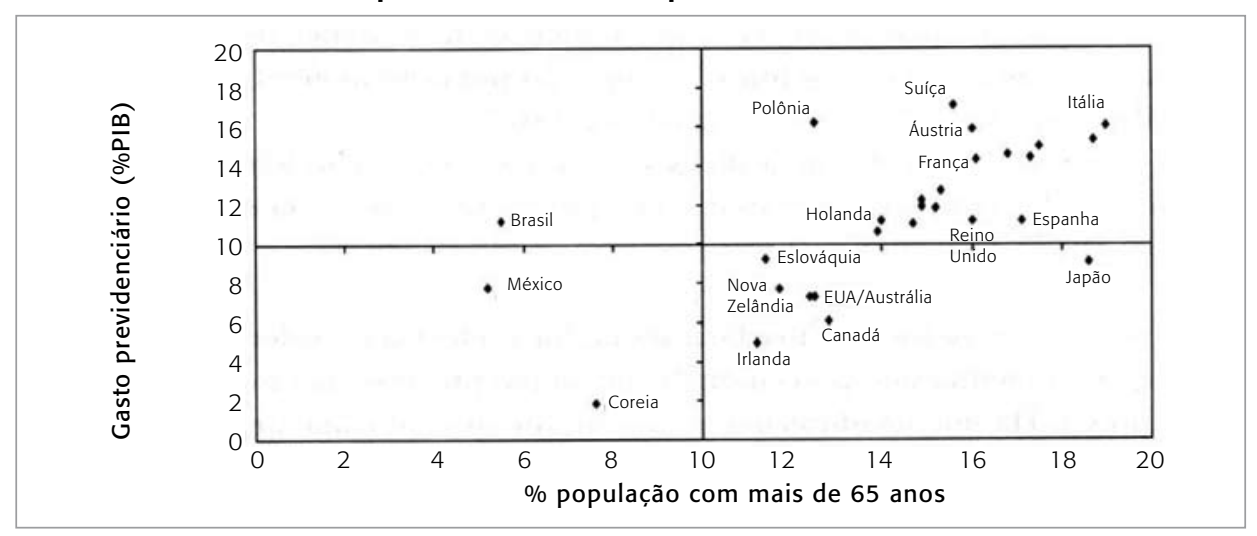

Fonte: Giambiagi (2007:93). 
Nota-se que o Brasil é o único país do grupo analisado com menos de $10 \%$ de idosos que gasta mais de $10 \%$ do PIB com previdência.

A necessidade de ajustes também é demonstrada pelos aportes crescentes do Tesouro Nacional para cobrir diferenças entre receitas e despesas. Nos gastos totais com a Previdência, o RGPS é a maior fonte de aumento de despesas, passando de 2,5\% do PIB em 1988, ano de aprovação da Constituição, para quase 5\% do PIB em 1994, quando foi lançado o Plano Real, superando 7\% do PIB em 2004 (Giambiagi, 2007).

Estas informações demonstram a necessidade e urgência de reformas. Demonstram também que o RGPS merece atenção especial em razão do desequilíbrio entre receitas e despesas e do impacto crescente nas contas nacionais. Assim, tanto pela complexidade do sistema previdenciário quanto pela importância do RGPS, este se constituiu no foco e delimitador deste artigo.

\section{Revisão da literatura}

Como vimos, as variáveis independentes usadas na análise de regressão surgiram de uma revisão de literatura que apontou fatores supostamente relevantes para a Previdência Social. Dessa mesma pesquisa, também surgiram os indicadores mais adequados para representar os fatores na análise quantitativa. Esses fatores e indicadores são comentados aqui.

\section{Fatores demográficos}

As taxas de fecundidade, mortalidade e migração determinam o perfil da população que é caracterizado pela distribuição dos indivíduos por idade e sexo. A distribuição por idade é importante porque influencia na razão entre beneficiários e contribuintes e no resultado de regimes de previdência como o RGPS (Santos, 2004). A distribuição por sexo é importante em razão das regras diferenciadas para aposentadoria das mulheres que se aposentam mais cedo, assim como pela esperança de vida maior que a dos homens (Giambiagi e colaboradores, 2004).

As projeções anuais do IBGE para a população brasileira com detalhamento por idade e sexo são apresentadas por Oliveira e colaboradores (2004). Também apresentam o método para realizar estimativas mensais a partir dos valores anuais e dois indicadores relativos à distribuição por idade e gênero. $\mathrm{O}$ 
primeiro indicador é a razão de dependência demográfica dos idosos (RDDI), definida como o quociente entre a população de 65 anos ou mais e o segmento populacional com idades entre 15 e 64 anos, num determinado ano. Outro indicador é a razão de gênero (RG), que neste artigo, representa a quantidade de homens de 65 anos ou mais para cada 100 mulheres de 65 anos ou mais, num determinado mês.

\section{Desemprego}

Segundo Caetano (2006:12), o "desempenho conjuntural do emprego afeta diretamente o resultado previdenciário, uma vez que a arrecadação se baseia primordialmente em folha de pagamentos". Em períodos de recessão diminuem os empregos, não se reduzem os benefícios pagos e quem preenche os requisitos para pleitear aposentadoria tende a requerê-la quando afetado pelo desemprego.

A taxa de desemprego, indicador adotado na análise de regressão, é definida como a razão entre o total de desempregados e a força de trabalho total, em que desempregados são indivíduos que, em determinado período de referência, procuraram emprego sem sucesso (Ramos, 2007). As taxas de desemprego disponíveis no Brasil foram analisadas quanto à abrangência geográfica, à quantidade de observações disponíveis no período estudado e à continuidade metodológica. A Pesquisa Nacional por Amostra de Domicílios (Pnad) do IBGE tem a maior abrangência geográfica, mas não dispõe de dados em quantidade suficiente em razão de sua periodicidade anual (Ramos, 2007). A Pesquisa Mensal de Emprego (PME), também do IBGE, é realizada mensalmente nas principais regiões metropolitanas do país. Mas passou por revisão metodológica em 2001 para se adequar a recomendações internacionais que gerou significativa descontinuidade nos dados (IBGE, 2007). A Pesquisa de Emprego e Desemprego (PED), da Fundação Sistema Estadual de Análise de Dados (Seade) do Governo do Estado de São Paulo, apresenta dados mensais por todo o período analisado com uniformidade metodológica e conceitual, mas sua abrangência está restrita à região metropolitana de São Paulo. Tal abrangência, entretanto, não limita a sua utilidade para este estudo, conforme demonstra a figura 2, na qual as pesquisas são comparadas. 
Figura 2

Taxas de desemprego da Pnad, PED e PME

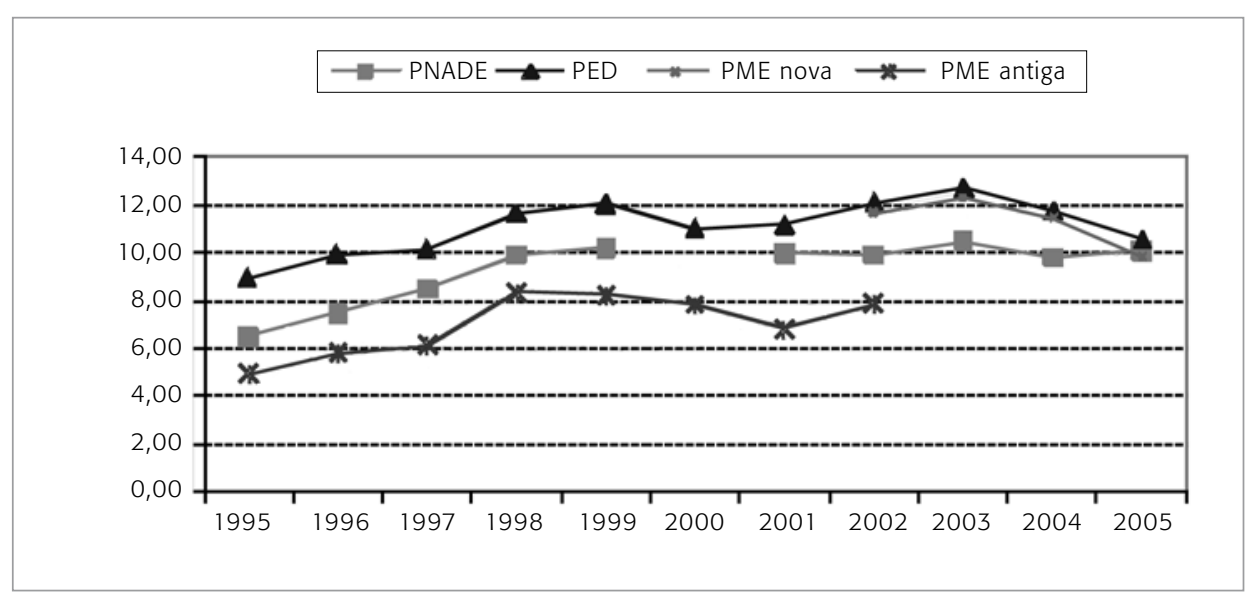

Fonte: Elaboração própria com base nos dados do Pnad, PED e PME.

A figura 2 permite concluir, em primeiro lugar, que a PED apresenta resultados muito semelhantes à "PME nova" depois que o IBGE promoveu as adequações metodológicas e conceituais aos padrões internacionais. Ela também ratifica a afirmação de Ramos (2007:30), que "embora as taxas metropolitanas sejam, de fato, mais elevadas, as variações tendem a ser bastante similares". Assim, foi selecionada a taxa de desemprego aberto divulgada na PED como indicador de desemprego neste artigo. Essa taxa é definida como o percentual dos indivíduos de 10 anos ou mais que procuraram trabalho de maneira efetiva nos 30 dias anteriores ao da entrevista e não exerceram nenhum tipo de atividade nos sete últimos dias (Seade, 2006).

\section{Inflação}

A inflação é mencionada em Além e Giambiagi (1997) como causa de corrosão do valor real dos benefícios, efeito que contribuía para amortecer a tendência de aumento das despesas do INSS. Paiva e colaboradores (2005) afirmam que, até 1994, a inflação corroía mensalmente os salários. Revela-se, nesse caso, o efeito desse fator na ponta de arrecadação previdenciária, uma vez que grande parte das receitas do RGPS está relacionada a contribuições sobre a remuneração dos segurados e sobre a folha de pagamentos das empresas. A inflação teria, portanto, efeitos na arrecadação e nos benefícios previdenciários. 
O índice nacional de preços ao consumidor (INPC) foi escolhido como índice de inflação neste artigo por ser usado como parâmetro de reajustes de benefícios do RGPS (Pinheiro e colaboradores, 2002).

\section{Taxa de juros}

Segundo Meyerson e colaboradores (2001), a taxa de juros influencia no rendimento dos ativos do sistema previdenciário americano cujo regime é semelhante ao nosso. A inclusão dessa taxa na pesquisa permite avaliar seus efeitos na Previdência Social brasileira.

A taxa Selic foi selecionada como indicador da taxa de juros porque é considerada a taxa básica de juros da economia e porque é usada para correção de dívidas com o INSS.

\section{Trabalho informal}

Na década de 1990, o mercado brasileiro passou por modificações com tendência para a flexibilização nas relações de trabalho. O RGPS, que tem a contribuição incidente sobre a folha salarial como uma das principais fontes de receita, foi afetado pela elevação do grau de informalidade nas relações trabalhistas (MPS, 1999). Beltrão e Pinheiro (2002:5) também afirmam que o "mercado de trabalho vem passando por importantes mudanças em direção à terceirização e à terciarização, com impactos significativos sobre receitas e custos do sistema previdenciário".

O indicador para trabalho informal usado aqui foi montado a partir da definição encontrada em Passos e colaboradores (2004:5) na qual são mencionados diversos estudos sobre "participação dos chamados 'informais' (na maioria das vezes tomados como trabalhadores sem carteira assinada e por conta própria) no total dos ocupados". Em conformidade com essa referência, foi construído um indicador de trabalho informal com dados da nova pesquisa mensal de emprego do IBGE definido pela relação $(\mathrm{SC}+\mathrm{CP}) / \mathrm{PO}$ onde:

$\mathrm{SC}$ = quantidade de empregados sem carteira assinada;

$\mathrm{CP}=$ quantidade de trabalhadores por conta própria;

$\mathrm{PO}=$ população ocupada.

É importante observar que, nas regressões em que foi utilizada essa série, o período considerado foi de março de 2002 a agosto de 2006. 


\section{Salário mínimo}

Giambiagi (2007), analisando o comportamento da Previdência Social após a última reforma do RGPS, afirma que "a despesa do INSS continuou crescendo fortemente, mas agora por outros fatores - essencialmente, auxílio-doença e salário mínimo". Paiva e colaboradores (2005) mostram que, em junho de 2005 , os benefícios iguais a um salário mínimo representavam $64,3 \%$ do total de benefícios emitidos. Oliveira e colaboradores (1997) mostram que, em 1995, os benefícios de salário mínimo representavam 70\% do total pago enquanto, do lado da receita, representavam menos de 15\% dos salários de contribuição. Essa assimetria também indica a relevância do salário mínimo para o RGPS.

A série de valores nominais do salário mínimo para o período tratado aqui foi usada na análise quantitativa.

\section{Rendimentos}

O crescimento nominal do rendimento dos trabalhadores afeta tanto as receitas como as despesas com benefícios da Previdência Social. À medida que a renda aumenta há um crescimento imediato na arrecadação. Por outro lado, os benefícios do futuro também serão maiores (Klieber, 2004).

A série de rendimentos médios nominais habituais (RMNH) do trabalho principal, divulgada pelo IBGE a partir de março 2002, foi escolhida como indicador de rendimentos aqui. Nas regressões em que foi utilizada esta série, o período considerado foi de março de 2002 a agosto de 2006.

\section{Variáveis previdenciárias}

Acabamos de relacionar os fatores que, segundo a literatura, influenciam na Previdência Social, especialmente no RGPS. Precisamos agora especificar as variáveis do sistema previdenciário que estão relacionadas a esses fatores e que atuarão como variáveis dependentes na análise de regressão. São elas as receitas previdenciárias, os benefícios previdenciários e os saldos previdenciários.

Os fundamentos técnicos e jurídicos que orientam a metodologia de aferição do resultado do RGPS são definidos pelo art. 68 da Lei Complementar n⿳o 101, de 4 de maio de 2001, que trata da escrituração e consolidação das contas públicas. Seguindo essas normas, o Ministério da Previdência Social (MPS) di- 
vulga mensalmente o saldo previdenciário (SP), também referido como resultado previdenciário (Pinheiro e colaboradores, 2002). Esse saldo é resultante da diferença entre receitas previdenciárias e benefícios previdenciários.

As receitas previdenciárias (RP) são constituídas pelas contribuições previstas na legislação. Elas são originadas de empresas e entidades equiparadas, empregadores domésticos e segurados, além de recolhimentos incidentes sobre a receita de concursos de prognósticos.

Os benefícios previdenciários (BP) são prestações pagas aos segurados ou dependentes nos casos de doença, invalidez, morte, idade avançada, maternidade e reclusão. Esses benefícios previdenciários não incluem os benefícios assistenciais pagos a idosos e deficientes, destinados a pessoas que não têm condições financeiras de contribuir para a Previdência Social. Mas os benefícios rurais, apesar de apresentarem forte conteúdo assistencial, são considerados benefícios previdenciários pela legislação e, portanto, fazem parte das despesas previdenciárias neste artigo.

As séries previdenciárias foram obtidas no Anuário Estatístico da Previdência Social (AEPS) e são constituídas por valores mensais correntes em milhões de reais para o período de janeiro de 1995 a agosto de 2006, totalizando 140 observações. Seguimos a prática corrente nos estudos sobre previdência em que esses valores são divididos pelo PIB para facilitar comparações internacionais e torná-los independentes de conversões cambiais ou índices inflacionários. Para isso, usamos a série histórica mensal do PIB, estimada e divulgada pelo Banco Central do Brasil, disponível em <www4.bcb.gov. $\mathrm{br} /$ ?SERIESTEMP $>$, cujos valores estão em conformidade com a nova metodologia de cálculo do PIB adotada pelo IBGE (BCB, 2007).

\section{Tratamento e análise dos dados}

Pela revisão de literatura, observamos que fatores econômicos e demográficos interagem e determinam fluxos financeiros da Previdência Social. A figura 3, inspirada em modelo elaborado por Meyerson e colaboradores (2001) para a previdência americana, demonstra as relações entre os fatores mencionados na revisão de literatura e as variáveis previdenciárias.

Nesta etapa, o trabalho consistiu em procurar relações entre os fatores identificados e as variáveis previdenciárias por meio de uma análise econométrica. A análise envolve métodos estatísticos que exigem rigorosa verificação de premissas e ajustes para que as conclusões sejam válidas. Apresentamos o essencial para a compreensão dos resultados. 
Iniciamos pelo tratamento das séries de receitas previdenciárias (RP), benefícios previdenciários (BP) e saldos previdenciários (SP), que foram divididos pelo PIB e submetidos a ajustamento sazonal. Assim, a variável efetivamente usada para receitas foi a série com ajustamento sazonal de receitas previdenciárias divididas pelo PIB, identificada como "sasRP" nas tabelas. Analogamente foram usadas "sasBP" e "sasSP" para os benefícios e saldos previdenciários ajustados e divididos pelo PIB.

Para atender ao requisito de linearidade, foi aplicada a raiz quadrada às séries que representam os fatores demográficos. A verificação de multicolinearidade resultou na eliminação de um dos indicadores e, por isso, a série que representa o fator demográfico neste trabalho é a raiz quadrada da razão de dependência demográfica dos idosos, identificada por "sqrtRDDI". Finalmente, para atender a requisito de normalidade, foi aplicada a função inversa na taxa de juros Selic, identificada por "inv Selic".

Terminada a fase de preparação dos dados e avaliação das suposições do método, passou-se à fase de execução das regressões em que as séries previdenciárias assumiram o papel de variável dependente e os indicadores tornaram-se as variáveis preditoras.

O arcabouço teórico que suporta a análise dos dados e as conclusões deste artigo é composto por análise de séries temporais e análise de regressão, com destaque para as premissas especiais que devem ser observadas quando o método de análise de regressão é aplicado em dados constituídos por séries temporais. Trata-se de um referencial teórico extenso que é apresentado aqui de forma bastante resumida com o objetivo de fornecer as referências que podem ser consultadas sobre os assuntos.

Como vimos, os indicadores aqui tratados serão constituídos por séries de valores mensais. É necessário, portanto, recorrer aos estudos de séries temporais apresentados por Morettin e Toloi (2006) e Downing e Clark (2005). Essas séries são conjuntos de medidas de uma grandeza em períodos consecutivos e apresentam alguns componentes, entre os quais, um componente sazonal caracterizado por flutuações recorrentes em períodos específicos do ano. Neste artigo, as séries que apresentaram componente sazonal foram ajustadas pelo método das médias móveis descrito em Downing e Clark (2005:309) e implementado no software SPSS versão 13.0. Outro conceito importante é o de estacionariedade. A maioria dos procedimentos de análise estatística de séries temporais supõe que estas sejam estacionárias e quando elas não apresentam tal característica pode ser necessário transformá-las por meio de operações de diferenciação (Morettin e Toloi, 2006). A verificação de estacionariedade é feita pelo teste aumentado de Dickey-Fuller (ADF) cujos 
detalhes e implementação no software EViews 5.0 são apresentados por Seiler (2004:279).

Figura 3

Modelo de interação entre os fatores e as variáveis previdenciárias

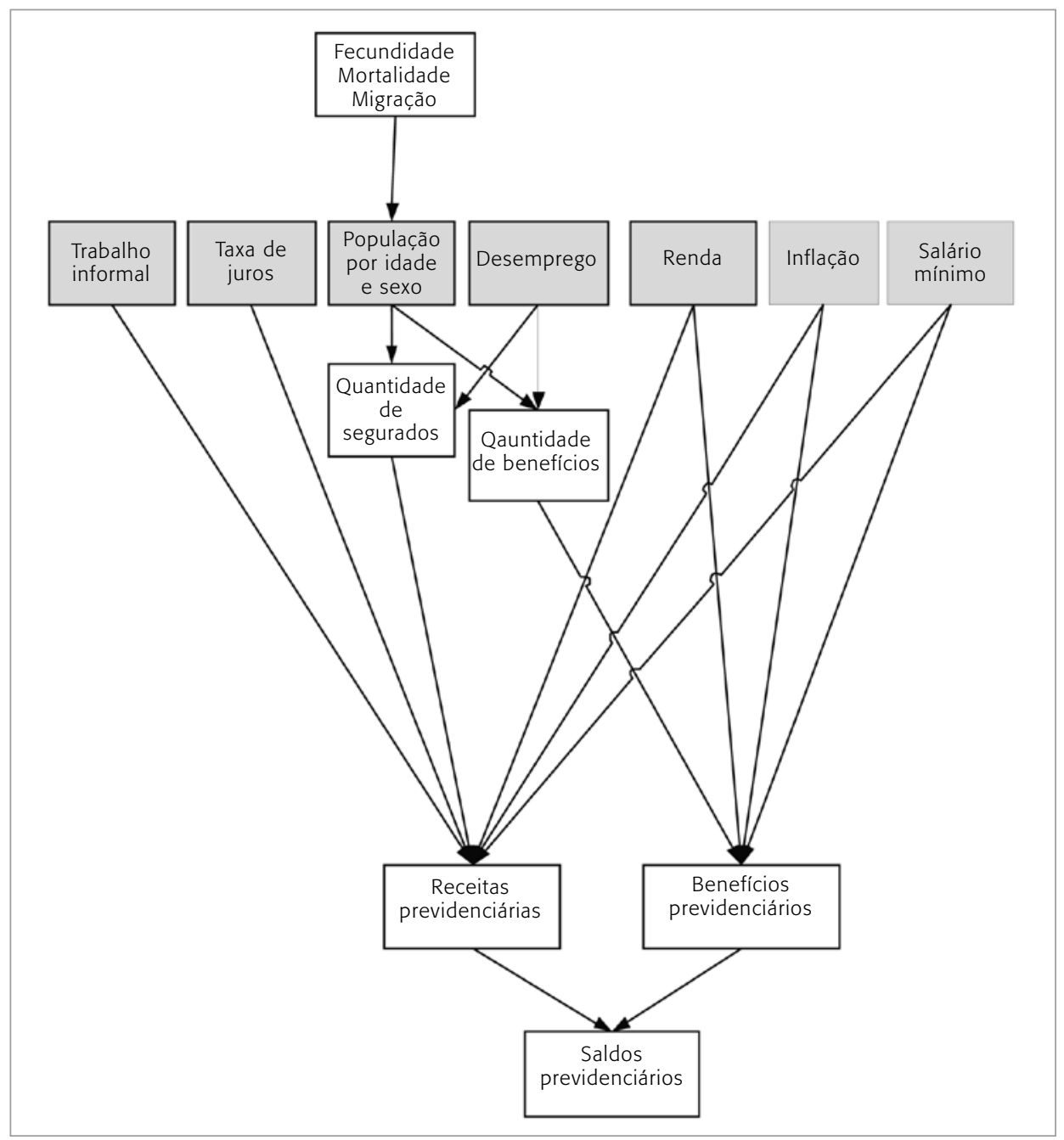

Fonte: Elaboração própria com base no modelo de Meyerson e colaboradores (2001).

O quadro 1 apresenta a configuração final das variáveis usadas no trabalho. Vale a pena salientar que as séries escolhidas para representar os fatores demográficos (sqrtRDDI e sqrsRG) apresentaram altíssima colineari- 
dade, indicada pelo coeficiente de correlação de $-0,999$. Por essa razão, apenas a série raiz quadrada da razão de dependência demográfica dos idosos (sqrtRDDI) foi escolhida, porque apresentou maior correlação com as variáveis previdenciárias.

Quadro 1

Identificação das variáveis

\begin{tabular}{|c|c|c|}
\hline $\begin{array}{l}\text { Variável } \\
\text { previdenciária }\end{array}$ & $\begin{array}{l}\text { sasBP } \\
\text { sasRP } \\
\text { sasSP }\end{array}$ & $\begin{array}{l}\text { Série com ajustamento sazonal de benefícios previdenciários } \\
\text { divididos pelo PIB } \\
\text { Série com ajustamento sazonal de receitas previdenciárias divididas } \\
\text { pelo PIB } \\
\quad \text { Série com ajustamento sazonal de saldos previdenciários divididos } \\
\text { pelo PIB }\end{array}$ \\
\hline Indicador & $\begin{array}{l}\text { Invselic } \\
\text { sqrtRDDI } \\
\text { INPC } \\
\text { SM } \\
\text { TD } \\
\text { RMNH } \\
\text { TI }\end{array}$ & $\begin{array}{l}\text { Função inversa da taxa de juros Selic } \\
\text { Raiz quadrada da razão de dependência demográfica dos idosos } \\
\text { Índice nacional de preços ao consumidor } \\
\text { Salário mínimo } \\
\text { Taxa de desemprego } \\
\text { Rendimentos médios nominais habituais } \\
\text { Trabalho informal }\end{array}$ \\
\hline
\end{tabular}

Como o conjunto de indicadores (variáveis preditoras) ficou constituído por sete séries, foi possível construir 127 subconjuntos resultantes das diferentes possibilidades de combinação dessas variáveis. Assim, para cada variável previdenciária, foram testados 127 modelos. Ao todo, 381 modelos foram obtidos nessa abordagem combinatória envolvendo as três variáveis previdenciárias. Os testes foram executados com auxílio do software SPSS versão 13.0 por meio da função autoregression com o método de Prais-Winsten. Trata-se de uma extensão da análise de regressão linear comum voltada para séries temporais que leva em conta a presença de resíduos autocorrelacionados e produz estimativas confiáveis dos coeficientes de determinação e dos níveis de significância das variáveis preditoras.

Todos os modelos com apenas uma variável independente foram selecionados para análise. Eles permitiram separar as variáveis que confirmaram as referências da literatura daquelas que não revelaram significância estatística na relação com as variáveis previdenciárias. Além desses, os modelos multivariados que apresentaram todos os coeficientes significantes ao nível de 5\% foram selecionados para análise. Para cada modelo selecionado foram veri- 
ficadas as premissas do método de análise de regressão por meio da análise de resíduos, incluindo testes de estacionariedade e cointegração. Além disso, quando submetidos ao software Eviews versão 5.0 para confirmação, os modelos selecionados apresentaram-se válidos com valores absolutos de "inverted $A R$ roots" menores que 1 (um). Assim, garantiu-se que nenhuma regressão espúria foi usada para fundamentar as conclusões deste artigo.

\section{Modelos selecionados}

Os modelos selecionados descritos são agora apresentados para os componentes de benefícios, as receitas e os saldos previdenciários.

\section{Benefícios}

Os modelos que envolvem os benefícios previdenciários (sasBP) e uma variável independente têm seus principais parâmetros apresentados na tabela 1.

Tabela 1

Modelos para benefícios com uma variável independente

\begin{tabular}{|lccccc|}
\hline \multicolumn{5}{|c|}{ Modelos com variável dependente sasBP e uma variável preditora } \\
\hline $\begin{array}{l}\text { Variável } \\
\text { independente }\end{array}$ & $\mathrm{R}^{2}$ & Durbin-Watson & Coeficiente & $\mathrm{t}$ & Significância \\
\hline SM & 0,692 & 2,051 & 0,000094 & 17,710 & 0,000 \\
RMNH & 0,477 & 2,094 & 0,000050 & 7,095 & 0,000 \\
sqrt RDDI & 0,671 & 2,039 & 0,837079 & 16,707 & 0,000 \\
inv SELIC & 0,005 & 2,441 & 0,005813 & 1,623 & 0,107 \\
TD & $-0,014$ & 2,436 & 0,000000 & 0,291 & 0,771 \\
INPC & $-0,011$ & 2,452 & 0,000000 & $-0,721$ & 0,472 \\
TI & $-0,039$ & 2,486 & 0,000092 & 0,081 & 0,936 \\
\hline
\end{tabular}

Nota-se que o salário mínimo (SM), a renda mensal nominal habitual (RMNH) e a variável que representa os fatores demográficos (sqrtRDDI) explicaram variações em benefícios previdenciários relativos ao PIB no período analisado ao nível de significância de 5\%. 
Entre os modelos selecionados, aquele que apresentou a variável estatística com maior poder preditivo para benefícios é constituído pelas variáveis sqrtRDDI e SM. Os parâmetros do modelo são apresentados na tabela 2 .

Tabela 2

Modelo multivariado para benefícios

\begin{tabular}{|ll|}
\hline Constante & $-0,082$ \\
& $(0,044)$ \\
sqrtRDDI & 0,453 \\
& $(0,003)$ \\
SM & 0,415 \\
& $(0,006)$ \\
R2 & 0,737 \\
Durbin-Watson & 2,017 \\
\hline
\end{tabular}

\section{Receitas}

Os modelos que envolvem as receitas previdenciárias (sasRP) e uma variável independente têm seus principais parâmetros apresentados na tabela 3 .

Quando tomadas individualmente, as variáveis de rendimentos médios nominais habituais (RMNH), salário mínimo (SM) e taxa de desemprego (TD) explicaram variações em receitas previdenciárias relativas ao PIB uma vez que apresentaram coeficientes significantes a $5 \%$.

$$
\text { Tabela } 3
$$

Modelos para receitas com uma variável independente

\begin{tabular}{|lccccc|}
\hline \multicolumn{5}{|c|}{ Modelos com variável dependente sasRP e uma variável preditora } \\
\hline $\begin{array}{l}\text { Variável } \\
\text { independente }\end{array}$ & $\mathrm{R}^{2}$ & Durbin-Watson & Coeficientes & $\mathbf{t}$ & Significância \\
\hline SM & 0,065 & 2,203 & 0,00001 & 3,416 & 0,001 \\
RMNH & 0,562 & 1,956 & 0,00003 & 8,366 & 0,000 \\
sqrt RDDI & 0,012 & 2,253 & 0,06962 & 1,920 & 0,057 \\
inv Selic & $-0,008$ & 2,287 & 0,00149 & 0,912 & 0,363 \\
\hline
\end{tabular}




\begin{tabular}{|lccccc|}
\hline \multicolumn{5}{|c|}{ Modelos com variável dependente sasRP e uma variável preditora } \\
\hline $\begin{array}{l}\text { Variável } \\
\text { independente }\end{array}$ & $\mathrm{R}^{2}$ & Durbin-Watson & Coeficientes & $\mathrm{t}$ & Significância \\
\hline TD & 0,027 & 2,228 & $-0,00052$ & $-2,421$ & 0,017 \\
INPC & $-0,012$ & 2,289 & $-0,00021$ & $-0,555$ & 0,580 \\
TI & $-0,016$ & 2,345 & $-0,00059$ & $-1,086$ & 0,282 \\
\hline
\end{tabular}

Entre os modelos multivariados para receitas previdenciárias, destacase aquele constituído por trabalho informal (TI) e salário mínimo (SM), cujos parâmetros são apresentados na tabela 4.

Tabela 4

Modelo multivariado para receitas

\begin{tabular}{|lc|}
\hline Constante & 0,065 \\
& $(0,000)$ \\
TI & $-0,242$ \\
& $(0,008)$ \\
SM & 0,742 \\
& $(0,000)$ \\
R2 & 0,611 \\
Durbin-Watson & 1,950 \\
\hline
\end{tabular}

\section{Saldos previdenciários}

Os modelos que envolvem os saldos previdenciários (sasSP) e uma variável independente têm seus principais parâmetros apresentados na tabela 5 .

A variável que representa os fatores demográficos (sqrtRDDI), o salário mínimo (SM) e os rendimentos (RMNH) explicaram variações no saldo previdenciário no nível de significância de 5\%.

Entre os modelos multivariados analisados, nenhum se mostrou estatisticamente significante. Aquele que apresentou o conjunto de variáveis estatísticas com maior poder preditivo para o saldo previdenciário foi composto pelo fator demográfico (sqrtRDDI) e pelo desemprego (TD). Entretanto, a significância da variável desemprego não pode ser considerada alta, conforme está na tabela 6. 
Tabela 5

Modelos para saldo previdenciário com uma variável independente

\begin{tabular}{|lccccc|}
\hline \multicolumn{5}{|c|}{ Modelos com variável dependente sasSP e uma variável preditora } \\
\hline Variável independente & $\mathrm{R}^{2}$ & Durbin-Watson & Coeficientes & $\mathbf{t}$ & Significância \\
\hline SM & 0,538 & 2,174 & $-8,2 \mathrm{E}-05$ & $-12,810$ & 0,000 \\
RMNH & 0,207 & 2,003 & $-2,6 \mathrm{E}-05$ & $-3,984$ & 0,000 \\
Sqrt RDDI & 0,748 & 2,023 & $-0,76750$ & $-20,179$ & 0,000 \\
inv SELIC & $-0,001$ & 2,613 & $-0,00533$ & $-1,340$ & 0,182 \\
TD & $-0,007$ & 2,586 & $-0,00069$ & $-1,043$ & 0,299 \\
INPC & $-0,014$ & 2,632 & 0,000132 & 0,172 & 0,864 \\
TI & $-0,015$ & 2,132 & $-0,00077$ & $-1,096$ & 0,278 \\
\hline
\end{tabular}

Tabela 6

Modelo multivariado para

saldos previdenciários

\begin{tabular}{|ll|}
\hline Constante & 0,210 \\
& $(0,000)$ \\
sqrtRDDI & $-0,829$ \\
& $(0,000)$ \\
TD & $-0,108$ \\
& $(0,018)$ \\
R2 & 0,779 \\
Durbin-Watson & 2,004 \\
\hline
\end{tabular}

\section{Conclusões}

Em relação aos benefícios previdenciários, o salário mínimo, os fatores demográficos e, em menor grau, os rendimentos destacaram-se no conjunto de dados analisados. Isso confirma a revisão de literatura na qual se apresentaram análises referentes ao altíssimo percentual de benefícios com valor de um salário mínimo e sobre a evolução da razão "segurados/contribuintes" em regimes de repartição simples. 
Para receitas previdenciárias, o destaque dos dados ficou com os rendimentos, fato que também confirma a literatura e os argumentos de autores que apontaram a relevância desse fator pelo RGPS ter como principal fonte de receitas a folha de pagamento das empresas. Em menor grau, verificou-se que o trabalho informal, a taxa de desemprego e o valor do salário mínimo também têm reflexos nas receitas previdenciárias.

Para o saldo previdenciário, destacaram-se também os fatores demográficos e o salário mínimo como principais variáveis preditoras de suas variações. Tais variáveis assumem importância especial porque o saldo previdenciário é o indicador final da diferença entre arrecadação e pagamento dos benefícios previdenciários do RGPS. Esse resultado ratifica a importância da adoção de medidas em prol do equilíbrio do sistema. Com a relevância dos fatores demográficos, demonstrada neste artigo, adiciona-se mais um argumento em favor de propostas dos especialistas que defendem a adoção de idade mínima para aposentadorias, requisito existente na previdência pública da grande maioria dos países. Com a relevância do salário mínimo para o saldo previdenciário, a proposta dos que defendem a utilização de indicadores de inflação para reposição do valor dos benefícios, desvinculando-os do salário mínimo para evitar aumentos reais dos inativos, também ganha mais um argumento.

As conclusões extraídas dos modelos selecionados neste artigo foram consolidadas e comparadas com os fatores e seus efeitos obtidos na revisão de literatura. O resultado é apresentado no quadro 2 .

Quadro 2

A literatura e o resultado da análise dos dados

\begin{tabular}{|c|c|c|c|c|c|c|}
\hline & \multicolumn{3}{|c|}{ Literatura } & \multicolumn{3}{|c|}{ Dados } \\
\hline & Receitas & Benefícios & Saldo & Receitas & Benefícios & Saldo \\
\hline Fatores demográficos & & $x$ & $x$ & & & \\
\hline Desemprego & $x$ & & $x$ & & & \\
\hline Inflação & $x$ & $x$ & & & & \\
\hline Taxa de juros & $x$ & & $x$ & & & \\
\hline Trabalho informal & $x$ & & $x$ & & & \\
\hline Salário mínimo & $x$ & $x$ & $x$ & & & \\
\hline Rendimentos & $x$ & $x$ & & & & \\
\hline
\end{tabular}

Observa-se que os modelos construídos a partir das séries temporais confirmam a grande maioria das afirmações dos especialistas. Conclui-se que 
os fatores demográficos, o salário mínimo, os rendimentos, o trabalho informal e o desemprego explicam variações nos principais componentes do Regime Geral de Previdência Social.

\section{Referências}

AEPS - Anuário Estatístico da Previdência Social: suplemento histórico 1980 a 2002, v. 3. Brasília: MPS, 2003.

- Base de Dados Históricos. Disponível em: <http://creme.dataprev.gov. br/infologo/inicio.htm>. Acesso em: 15 dez. 2006.

ALÉM A. C. D; GIAMBIAGI F. Despesa previdenciária: análise da sua composição, efeitos da inflação e bases para uma alternativa intermediária de reforma. Texto para discussão n. 374. Rio de Janeiro: PUC, 1997.

BCB. Sistema gerenciador de séries temporais, v. 1.2. Módulo público. Disponível em: <https://www3.bcb.gov.br>. Acesso em: 16 abr. 2007.

BELTRÃO, K; PINHEIRO, S. S. Uma avaliação dos dados da PNAD com respeito à "Previdência Social" - população ativa e inativa. Texto para Discussão n. 871. Rio de Janeiro: Ipea, 2002.

CAETANO, M. A. Determinantes da sustentabilidade e do custo previdenciário: aspectos conceituais e comparações internacionais. Texto para Discussão n. 1.226. Brasília: Ipea, 2006.

DOWNING, D.; CLARK, J. Estatística aplicada. 2. ed. São Paulo: Saraiva, 2005.

GIAMBIAGI, F. Reforma da previdência: o encontro marcado. Rio de Janeiro: Elsevier, 2007.

et al. Diagnóstico da Previdência Social no Brasil: o que foi feito e o que falta reformar? Texto para Discussão n. 1.050. Rio de Janeiro: Ipea, 2004.

IBGE. Pesquisa mensal de emprego. Disponível em: <www.ibge.gov.br/estatistica/ indicadores/trabalhoerendimento > . Acesso em: 15 jan. 2007.

JAMES, E. Novos sistemas previdenciários: experiências, evidências e questões pendentes. Brasília: MPAS/SPS, 2001. (Coleção Previdência Social - A economia política da Reforma da Previdência — Série Traduções).

KLIEBER, E. J. et al. Assumptions used to project Social Security's financial condition. Washington, DC: American Academy of Actuaries, January 2004. 
MEYERSON, N. et al. Uncertainty in Social Security's long-term finances: a stochastic analysis. Congress of the United States - Congressional Budget Office, 2001.

MINISTÉRIO DA PREVIDÊNCIA SOCIAL. Previdência e o trabalhador informal: medidas para ampliar a cobertura do sistema. Informe de Previdência Social, Brasília, MPAS/SPS, v. 11, n. 8, 1999.

. Panorama da Previdência Social brasileira. Brasília: MPS/ACS, 2004.

MORETTIN, P. A.; TOLOI, C. M. C. Análise de séries temporais. São Paulo: Edgard Blücher, 2006.

NESS W. L. Jr.; MONTEZANO, R. M.; GUEDES E. Previdência Social do Brasil: evolução recente, perspectivas e princípios para reformulação. Revista Brasileira de Mercado de Capitais, v. 17, p. 55-156, 1992.

OLIVEIRA, F. E. B; BELTRÃO, K; FERREIRA, M. Reforma da Previdência. Texto para Discussão n. 508. Rio de Janeiro: Ipea, 1997.

OLIVEIRA, J. C; ALBUQUERQUE, F. R. P. C; LINS, I. B. Projeção da população do Brasil por sexo e idade para o período 1980-2050 - Revisão 2004: metodologia e resultados. Disponível em: <www.ibge.gov.br>. Rio de Janeiro: IBGE, 2004.

PAIVA, L. H; ANSILIERO, G; PASSOS A. F. Impactos da Previdência Social sobre a pobreza. Nota Técnica n. 032/05 MPS/SPS/CGEP. Brasília: MPS, 2005.

PASSOS, A. F; ANSILIERO, G.; PAIVA, L. H. Mercado de trabalho: tendências da última década e implicações para a Previdência Social. Informe de Previdência Social, Brasília, MPS/SPS, v. 16, n. 9, 2004.

PINHEIRO, V. C.; ARRUDA, G. A.; SANTANA, R. L. F. Déficit da Previdência Social: considerações metodológicas. Informe de Previdência Social, Brasília, MPS/SPS, v. 14, n. 1, 2002.

RAMOS, L. O desempenho recente do mercado de trabalho brasileiro: tendências, fatos estilizados e padrões espaciais. Texto para Discussão n. 1.255. Rio de Janeiro: Ipea, 2007.

SANTOS, N. M. G. Um estudo prospectivo sobre a Previdência Social brasileira. 2004. Tese (Doutorado) - Coppe/UFRJ, Rio de Janeiro.

SCHWARZER, H. Paradigmas de Previdência Social rural: um panorama da experiência internacional. Texto para Discussão n. 729. Rio de Janeiro: Ipea, 2000. 
SEADE - Fundação Sistema Estadual de Análise de Dados. Pesquisa de emprego e desemprego. Disponível em: <www.seade.gov.br/produtos/ped>. Acesso em: 10 set. 2006.

SEILER, M. J. Performing financial studies: a methodological cookbook. Prentice Hall, 2004.

THOMPSON, L. Mais velha e mais sábia: a economia dos sistemas previdenciários. Brasília: MPAS/SPS, 2000. (Coleção Previdência Social. Série Debates). 